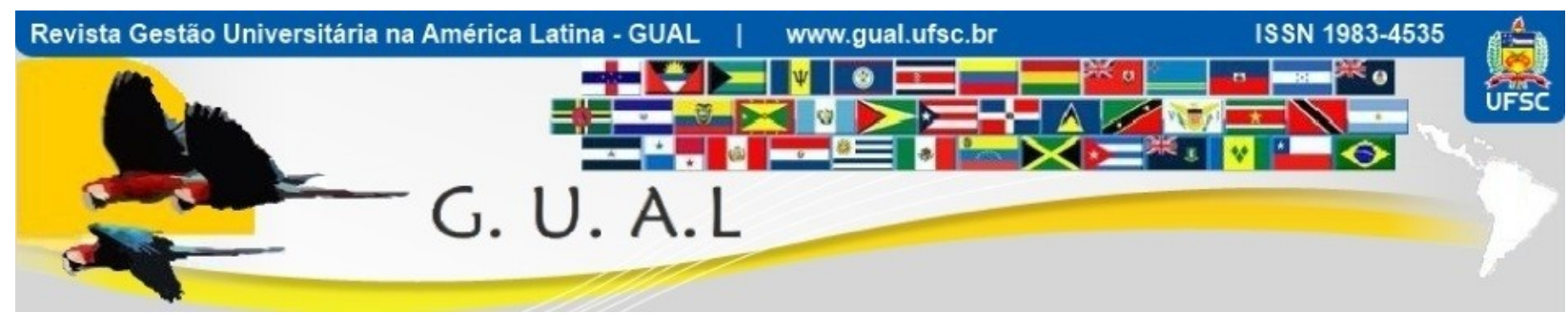

DOI: http://dx.doi.org/10.5007/1983-4535.2015v8n2p177

\title{
A UTILIZAÇÃO DO ESTUDO DE CASO EM PESQUISAS SOBRE GESTÃO ESCOLAR
}

THE USE OF CASE STUDY IN RESEARCH ON SCHOOL MANAGEMENT

\author{
Dyogo Neis, Doutorando \\ Universidade Federal de Santa Catarina - UFSC \\ dyogoneis@hotmail.com \\ Maurício Fernandes Pereira, Doutor \\ Universidade Federal de Santa Catarina - UFSC \\ mfpcris@gmail.com
}

Recebido em 10/maio/2014

Aprovado em 17/abril/2015

Sistema de Avaliação: Double Blind Review

Esta obra está sob uma Licença Creative Commons Atribuição-Uso. 


\begin{abstract}
RESUMO
Este artigo tem como objetivo analisar como o Estudo de Caso está sendo utilizado nas pesquisas sobre Gestão Escolar na realidade brasileira. A pesquisa se caracteriza como bibliográfica qualitativa, no qual se empregou o método de levantamento de fontes secundárias. Em suma, após buscas avançadas em três bases de dados de artigos científicos, selecionamos os artigos que efetivamente utilizaram o estudo de caso como método de pesquisa para analisar a Gestão Escolar no contexto nacional. Estas pesquisas foram avaliadas a partir de dois momentos. Inicialmente, coletamos os dados gerais dos artigos em caráter meramente descritivo. Na sequência, analisamos qualitativamente as diretrizes do estudo de caso aplicadas nestes artigos. Nossa avaliação indica que as pesquisas se caracterizam como estudos de caso único, qualitativos e empregam múltiplos instrumentos de coleta de dados; que a maioria dos autores descreve como os dados foram analisados; que há poucas pesquisas instrumentais; que inexiste pesquisa avaliativa no que se refere aos objetivos; e que os autores não apresentam indícios característicos da perspectiva epistemológica positivista. Por fim, concebemos que a utilização do Estudo de Caso nas pesquisas sobre Gestão Escolar tem abrangência e consistência suficiente para demonstrar detalhes importantes da Gestão Escolar no contexto brasileiro.
\end{abstract}

Palavras-chave: Metodologia. Estudo de caso. Gestão Escolar.

\begin{abstract}
This article aims to analyze how the case study has been used in research on School of Management in Brazil. The research is characterized as qualitative literature, because we used the withdrawal method of secondary sources. In short, after performing advanced searches in three scientific articles databases, select the articles that used the case study as a research method to analyze the School of Management in the national context. These articles were evaluated in two ways. First, we collect general data of articles descriptively. And then, we analyze the characteristics of case study applied. Our review indicates that research are characterized as unique case studies, qualitative case studies and employ multiple data collection instruments; most authors that describes how the data were analyzed; there are few instrumental research; that does not exist evaluative research in relation to the objectives; and that the authors do not show characteristic signs of positivist epistemological perspective. Finally, we conclude that the use of the Case Study in research on School of Management has sufficient scope and consistency to show important details of the School of Management in the Brazilian context.
\end{abstract}

Keywords: Methodology. Case study. School of Management. 


\section{INTRODUÇÃO}

No Brasil, o acesso à educação é direito de todos e está garantido na legislação. Não obstante, de acordo com o artigo 206 da Constituição Brasileira de 1988, a educação deve estar acompanhada de qualidade. Esta garantia é reforçada por inúmeros dispositivos, dentre eles, a Lei de Diretrizes e Bases da Educação Nacional - nº 9.394/96.

No entanto, a educação brasileira ainda possui muitas deficiências, especialmente no que diz respeito à qualidade. A história indica que o Estado se preocupou mais em incluir a sociedade no processo educativo do que propriamente na qualidade do ensino. Este fenômeno ocorreu principalmente por meio do Plano Decenal de Educação para Todos 1993-2003, que já em 1998 conseguiu aumentar a população em idade escolar atendida para 96\%, resultado acima da meta estipulada (CENPEC, 2000). Houve progressos no que diz respeito à universalização do ensino básico em todo o país, contudo, os ganhos quantitativos ocorreram em detrimento da qualidade geral do sistema (COELHO, 2008).

As edições mais recentes do Índice de Desenvolvimento da Educação Básica (IDEB) e do Programme for Internacional Student Assessment (PISA) indicam que o desempenho das escolas brasileiras ainda é sofrível quando comparado à média dos demais países (INEP, 2014; OCDE, 2014). Neste contexto, emerge o Plano Nacional de Educação (PNE), que, dentre outros objetivos, visa incluir o Brasil no nível médio dos países da OCDE até o horizonte estratégico deste projeto (BRASIL, 2014). Isso equivale afirmar que o país quer melhorar o seu desempenho médio nos anos iniciais de 3.2 pontos em 2007 para 6.0 pontos em 2021, uma meta no mínimo desafiadora.

O processo de qualificação da educação brasileira passa, necessariamente, pela Gestão Escolar (TODOS PELA EDUCAÇÃO, 2014). Esta prerrogativa ganha ainda mais legitimidade quando se constata que o aperfeiçoamento da Gestão das escolas brasileiras é uma das vinte metas do Plano Nacional de Educação (BRASIL, 2014) e um dos principais desafios apontados pelo projeto Mapa do Buraco (BARBOSA et al., 2014).

Assim, os estudos sobre Gestão Escolar passam, cada vez mais, a ocupar a agenda dos pesquisadores. A pesquisa de Martins e Silva (2011) indica que, apesar do tema ser abordado desde meados de 1980, sobretudo na área de Educação, as discussões sobre Gestão Escolar recebem maior notoriedade na literatura a partir de 2000, ocupando, desde então, um espaço legítimo e importante tanto no cenário acadêmico quanto no cenário das formulações de políticas públicas do país. Para compreender a Gestão Escolar e seus temas correlatos, é 
necessário entender os detalhes deste processo, ou seja, as pesquisas devem assumir certo nível de profundidade. Assim, os métodos e as estratégias de pesquisas qualitativas passam a ocupar lugar de destaque nestas discussões (MARTINS; SILVA, 2011; FELDHAUS, PEREIRA, 2013).

Neste sentido, o estudo de caso, um método qualitativo capaz de apreender o suficiente sobre o caso para absorver os significados complexos de um fenômeno específico (STAKE, 2000; GODOY, 2006), passa a ser uma possibilidade capaz de compreender, de modo consistente e aprofundado, a prática da Gestão nas instituições escolares brasileiras. Entretanto, nem sempre este método é utilizado de modo consistente e adequado com os seus objetivos, como apontam as pesquisas de Mariz et al. (2005), de Godoy (2006), de AlvezMazzotti (2006) e de Consoli et al. (2008).

Deste modo, o presente artigo visa analisar como o Estudo de Caso está sendo utilizado nas pesquisas sobre Gestão Escolar na realidade brasileira.

\section{REFERENCIAL TEÓRICO}

Este capítulo está estruturado em duas seções, que apresentam os conceitos e as premissas teóricas de gestão escolar e de estudo de caso, respectivamente.

\subsection{GESTÃO ESCOLAR}

As escolas são organismos vivos e dinâmicos e compreendem um contexto social, econômico e cultural peculiar. Ao serem entendidas como organizações caracterizadas por uma rede de relações entre diversos elementos que nelas atuam ou interferem direta ou indiretamente, sua direção demanda um novo enfoque e é justamente esta lacuna que a gestão escolar visa atender. Portanto, abrange a dinâmica das interações em decorrência do trabalho como prática social, além do seu próprio negócio refletir na sociedade em âmbito geral (LUCK, 2000).

Neste sentido, mesmo quando constituída em uma determinada política educacional governamental, a gestão escolar reflete, diariamente, diversas práticas específicas, pois se contextualizam em nível local em função das relações sociais que se estabelecem no contexto da comunidade escolar. Assim, as políticas estatais são consideradas diretrizes de sistemas educacionais que nas escolas assumem dinâmicas distintas, seja pela ação dos sujeitos envolvidos ou pela realidade econômico-social em que se constituem (ALVES; GARCIA, 2002; LUCK, 2007). 
$\mathrm{Na}$ concepção de Ribeiro e Chaves (2012) a gestão escolar é o processo que operacionaliza e implementa as ações e políticas da unidade escolar, podendo ser centralizadora, controladora, produtivista, competitiva e de modo geral, vinculada a demandas do mercado. Em contrapartida, pode também assumir o caráter democrático, autônomo e participativo, o que tende a elevar o seu compromisso com os interesses da sociedade. Deste modo, há dois modelos de gestão predominantes no contexto brasileiro: um pautado na perspectiva gerencialista, outro na perspectiva democrática. O primeiro modelo está intimamente relacionado à reforma do Estado brasileiro, cujo enfoque central consiste em transportar para o sistema escolar os modelos desenvolvidos nas empresas, com vistas a adaptar a educação à lógica do mercado. Já na gestão escolar democrática, há maior participação da coletividade e maior autonomia na tomada de decisão (RIBEIRO; CHAVES, 2012).

Sob um ponto de vista similar, Cheng (2010) profere que a educação está passando por um processo evolutivo que pode ser entendido a partir de três modelos de gestão escolar. No primeiro, a estratégia escolar é uma forma de melhorias internas, baseada predominantemente em um tipo de racionalidade instrumental, com foco no aprimoramento técnico das operações internas em ensino, aprendizagem e gestão. As iniciativas-chave são comumente orientadas para o curto prazo e restritas a regulamentos burocráticos.

No segundo, as reformas estão direcionadas para a garantia da qualidade das escolas frente aos interesses dos agentes internos e externos. Este modelo de gestão enfatiza a eficiência na interação entre a escola e a comunidade, tipicamente definida pela satisfação das partes interessadas, competição baseada no mercado e prestação pública de contas. Consequentemente, está orientada por uma racionalidade mercadológica, geralmente encontrada nas empresas, sendo justamente esta a causa da principal limitação: em função do desempenho, a orientação para o mercado induz o desvio dos valores e significados centrais da educação (CHENG, 2010).

O terceiro modelo de gestão escolar emerge da reforma educacional com ênfase na efetividade futura, frequentemente definida pela relevância da educação para o desenvolvimento de indivíduos e de sua sociedade. Trata-se de um novo paradigma educacional que engloba múltiplas inteligências contextualizadas, globalização, localização e individualização (CHENG, 2010).

É possível relacionar estes modelos com as três dimensões de qualidade da gestão pública propostas por Lima (2005), a saber: eficiência, eficácia e efetividade. O primeiro 
modelo visa eficiência, pela via da melhoria contínua nos processos e operações escolares, sem a preocupação com os resultados dessa melhoria. O segundo modelo enfoca a eficácia, posto que as metas sobre indicadores de desempenho e a competição entre as escolas são colocados no centro da gestão educacional. Já o terceiro modelo tem em vista a efetividade, ao buscar propósitos e resultados finais da educação (LIMA, 2005; CHENG, 2010).

A partir destas concepções, pode-se afirmar que o modelo de gestão escolar dominante no Brasil ainda é prioritariamente interno, com foco nos regulamentos e na organização escolar para um modelo orientado para os resultados do mercado, neste caso, auferidos por meio de avaliações de desempenho. A divulgação em larga escala dos resultados, de forma comparada com outras unidades escolares, gera uma espécie de competição pelo desempenho (FELDHAUS, PEREIRA, 2013).

\subsection{ESTUDO DE CASO}

O estudo de caso é considerado um dos procedimentos mais importantes para uma pesquisa qualitativa (TRIVIÑOS, 1987; EISENHARDT, 1989; GODOY, 2006; YIN, 2009). Tendo como propósito fundamental analisar intensivamente uma determinada unidade social, o estudo de caso tem se tornado uma das estratégias de pesquisa mais utilizadas nas ciências sociais. Assim, constitui-se como um método capaz de apreender o suficiente sobre o caso para absorver os significados complexos de um fenômeno específico (STAKE, 2000; GODOY, 2006).

O estudo de caso pode ser utilizado de diversas formas. Alguns autores, como Eisenhardt (1989), Godoy (1995) e Yin (2009), defendem a prática do estudo de caso como uma estratégia de pesquisa compostas por uma série de etapas previamente definidas. Estes autores, inclusive, propõem um referencial metodológico para a utilização do estudo de caso. Entretanto, existe outra vertente, capitaneada por Stake (2000), que defende o estudo de caso como uma opção metodológica mais ampla, que dependendo exclusivamente do objetivo pode seguir uma linha diferente, ou seja, sem necessariamente seguir etapas previamente estabelecidas.

Eisenhardt (1989) concebe que o estudo de caso é uma estratégia de pesquisa que visa o entendimento da dinâmica de um determinado contexto. A pesquisa pode ser sob um único caso ou de diversos casos, mantendo a possibilidade de analisá-los por diferentes perspectivas, além de poder ser utilizado para realizar uma descrição, testar uma teoria ou gerar uma nova teoria. Não obstante, Yin (2009) afirma que esta estratégia de pesquisa deve 


\section{A UTILIZAÇÃO DO ESTUDO DE CASO EM PESQUISAS SOBRE GESTÃO ESCOLAR \\ DOI: http://dx.doi.org/10.5007/1983-4535.2015v8n2p177}

ser utilizada em casos que envolvem questões do tipo "como" ou "por que", em pesquisas que o investigador possui pouco controle sobre os fenômenos e quando o foco de análise trata-se de um fenômeno contemporâneo em um determinado contexto (YIN, 2009).

No entanto, nem tudo capaz de ser estudado isoladamente se caracteriza como um caso. Stake (2000) afirma que o caso é uma entidade complexa, localizada em um ambiente ou incorporado em uma determinada situação , portanto, é entendido como um sistema delimitado cujas partes se envolvem. E é justamente neste sentido que o estudo de caso ganha notoriedade e, ao mesmo tempo, complexidade, pois se por um lado possibilita o entendimento aprofundado de um determinado fenômeno , por outro, nem sempre é simples identificar os limites do caso a ser estudado. Esta definição tem sido considerada um dos pontos mais controversos desta estratégia de pesquisa, sobretudo quando se pretende ter como base a possibilidade de generalizar as conclusões.

Neste sentido, em artigo que busca esclarecer os frequentes mal-entendidos acerca do estudo de caso, Flyvbjerg (2006) aponta o entendimento equivocado que muitos críticos possuem sobre o fato desta estratégia de pesquisa ser menos útil que outros métodos no desenvolvimento de teorias, pois o estudo de caso seria útil apenas para a formulação de novas hipóteses, mas não para testá-las. $\mathrm{O}$ autor contrapõe esta crítica ao tempo que concebe uma dinâmica para a seleção de casos, admitindo desde amostras aleatórias, até casos extremos ou críticos. Para o nosso propósito, mais do que analisar esta classificação é relevante compreender a proposta de Flyvbjerg (2006) no que diz respeito à definição de um caso "paradigmático", isto é, aquele que destaca características mais gerais das sociedades em questão. A partir da impossibilidade de estabelecer procedimentos para determinar com segurança o que proporciona valor a determinados casos e não a outros, o autor avança com duas ideias centrais: a intuição e a experiência não podem ser negligenciadas no processo de seleção do caso; e, mais importante que garantir a identificação de um caso paradigmático, o pesquisador deve conseguir julgar a pertinência da sua escolha no decorrer da pesquisa, não apenas na questão da representatividade, mas também de acordo com seus critérios particulares.

Eisenhardt (1989) afirma que no momento da escolha dos casos que se pretende pesquisar, a preferência é para casos em que haja maior probabilidade de replicar ou ampliar a teoria estudada, apesar da escolha poder ser aleatória ou randômica. Logo, trata-se de um procedimento metodológico que enfatiza o entendimento de um determinado contexto sem negligenciar a importância da representatividade (LLEWELLYN; NORTHCOTT, 2007). 


\section{A UTILIZAÇÃO DO ESTUDO DE CASO EM PESQUISAS SOBRE GESTÃO ESCOLAR \\ DOI: http://dx.doi.org/10.5007/1983-4535.2015v8n2p177}

Relacionados a estes critérios, Stake (2000) concebe diretrizes capazes de identificar o que de fato constitui um caso representativo, a saber: a natureza do caso, em especial a sua atividade e o seu funcionamento ; o histórico do caso ; a sua situação geográfica ; o seu contexto (físico, econômico, político, legal, etc.); a disponibilidade das informações que se pretende recolher; e, principalmente, a oportunidade de aprendizagem. Este último esclarece a importância de definir um caso com o qual o pesquisador possa aprender mais, assim, pode-se optar pelo caso mais acessível ou por aquele com o qual seja viável despender mais tempo para o aprofundamento necessário (STAKE, 2000; FLYVBJERG, 2006).

A definição do caso está, portanto, embasada no intuito da pesquisa. Deste modo, ainda que admita que o intuito de sua proposta não seja restritivo, Stake (2000) apresenta três tipos de estudo de caso a partir de seu objetivo: intrínseco, instrumental e coletivo. No estudo de caso intrínseco, busca-se compreender um determinado caso pelo interesse do pesquisador, ou seja, é despertado por aquele caso particular. Assim, se difere do que o autor denomina de estudo de caso instrumental, que parte do princípio que o caso será capaz de promover a compreensão de um fenômeno mais amplo ou até mesmo avançar em uma teoria , portanto, o caso é considerado secundário. Por fim, expõe o estudo de caso coletivo, no qual o pesquisador investiga conjuntamente alguns casos para investigar um dado fenômeno, ou seja, pode ser entendido como um estudo de caso instrumental mais amplo.

A compreensão de um caso particular ocorre basicamente por meio de comparações de outros casos que o leitor possui conhecimento. O que pode ser conhecido para um caso, pode não ser verdade para outro, mesmo que seja similar. A transferência de conhecimento é um aspecto de difícil compreensão e é neste contexto que o entendimento de como um caso particular pode gerar conhecimento para o entendimento de um aspecto geral recebe notoriedade, sobretudo diante da oposição com os métodos experimentais que buscam a generalização através da indução (GODOY, 2006). Neste sentido, Stake (2000) chega a se perguntar: O que se pode aprender em um único caso? Este aprendizado está relacionado com o fato do caso ser semelhante ou diferente de outros casos conhecidos e é justamente aqui que se encontra a principal contribuição desta estratégia de pesquisa. Para alcançar a "generalização naturalística", os pesquisadores relatam seus casos sabendo que eles serão comparados a outros, por isso, buscam descrever os detalhes para que o próprio leitor seja capaz de realizar suas próprias comparações com o que foi observado sobre o fenômeno em outros contextos. Assim, entende-se o estudo de caso como um pequeno passo para a 


\section{A UTILIZAÇÃO DO ESTUDO DE CASO EM PESQUISAS SOBRE GESTÃO ESCOLAR \\ DOI: http://dx.doi.org/10.5007/1983-4535.2015v8n2p177}

generalização, porém generalizações e teorizações não podem ser tão fortes a ponto de afastar o pesquisador do entendimento do caso por si mesmo (STAKE, 2000).

Godoy (2006) afirma que a capacidade de generalização é uma das principais críticas ao estudo de caso, no entanto, como oportunamente exposto por Flyvbjerg (2006), pode-se tratar também de um mal-entendido conceitual. A história da ciência demonstra diversas descobertas científicas realizadas com a escolha cuidadosa de experimentos, casos e experiências que foram fundamentais no desenvolvimento da física de Newton, de Einstein e de Bohr, por exemplo. Isto não significa afirmar que o estudo de caso é sempre apropriado ou relevante como método de pesquisa ou que grandes amostras aleatórias não possuem valor, no entanto, a opção por esta estratégia de pesquisa deve estar de acordo com o problema de pesquisa e suas circunstâncias. Stake (2000) complementa que nem tudo precisa ser generalizado, tanto é que a maior parte das pesquisas é feita por indivíduos que tem interesse intrínseco no caso e pouco interesse no avanço da ciência. Ademais, quando esclarece o mal entendido relacionado à importância do entendimento teórico e prático relacionado ao contexto, Flyvbjerg (2006) afirma que a proximidade dos estudos de caso com situações da vida real e sua riqueza de detalhes são importantes para o desenvolvimento de uma visão detalhada da realidade, contribuindo, inclusive, para o próprio processo de aprendizagem do pesquisador no desenvolvimento das habilidades necessárias para realizar uma boa pesquisa.

Neste sentido, o intuito do estudo de caso não é representar o mundo, mas representar o caso. Para isto, o pesquisador deve fornecer razões para validar tanto as observações quanto as generalizações (STAKE, 2000; GODOY, 2006). Stake (2000) afirma que um estudo de caso coerente segue práticas de análise disciplinadas e de triangulação para trazer à tona o que merece ser chamado de conhecimento empírico do que é opinião e preferência. $\mathrm{O}$ autor concebe que a triangulação tem sido geralmente considerada um processo de utilização de múltiplas percepções para esclarecer o significado, verificando a repetição de uma observação ou interpretação. Esta premissa ajuda a responder outro mal-entendido abordado por Flyvberg (2006): o estudo de caso tem uma tendência maior na verificação das noções pré-estabelecidas pelo pesquisador. Embora não a recuse, o autor esclarece que este problema não se limita ao estudo de caso, pois é possível observá-lo em praticamente todos os métodos, inclusive quantitativos, haja vista que os métodos quantitativos na realidade também são intrinsecamente qualitativos e possivelmente arbitrários. No entanto, o autor deixa claro que o problema realmente é mais observado nos métodos qualitativos e, para evitá-lo, devem ser 
utilizados mecanismos para registrar as observações de forma que os achados que contrapõem seus pensamentos não sejam negligenciados.

Por fim, o último mal entendido descrito no trabalho de Flyvbjerg (2006) aborda a dificuldade de resumir os estudos de caso. Entretanto, o autor afirma que uma narrativa particularmente difícil de resumir não é um problema, pelo contrário, geralmente é um sinal de que o estudo descobriu uma problemática rica. Portanto, nem sempre o estudo de caso deve ser resumido e buscar a generalização, premissas nas quais os críticos têm como pressuposto. Assim, por meio dos esclarecimentos de Flyvbjerg (2006), é possível perceber que existe certo preconceito no mundo acadêmico à escolha do estudo de caso como estratégia de pesquisa.

Justamente neste sentido, o artigo "They have tied me to a Stake: reflections on the art of case study research" narra a história de uma forma de prejulgamento de Whatts (2007) em relação ao estudo de caso. Michael Whatts, então aluno de pós-graduação na University of East Anglia, foi apresentado ao estudo de caso pelo livro Art of Study Research, que concebe as premissas desta estratégia de pesquisa ao tempo que expõe um estudo de caso sobre a Escola Harper. Deste modo, Whatts (2007) demonstra sua inquietação no momento que se deparou pela primeira vez com o relato em profundidade de uma pesquisa caracterizada por esta abordagem de pesquisa. Embora reconheça no final de sua reflexão a capacidade de contribuição do estudo de caso em relação ao progresso científico, Whatts (2002) apresenta sua inquietação com a forma de apresentar o caso.

\section{PROCEDIMENTOS METODOLÓGICOS}

Para analisar o uso do estudo de caso nas pesquisas sobre Gestão Escolar, realizamos buscas avançadas em três bases de dados de artigos científicos nacionais, a saber: Portal de Periódico CAPES/MEC, Scientific Periodicals Electronic Library (Spell) e Ebsco Host. Em cada uma destas bases, pesquisamos os artigos científicos que tivessem no título, no resumo ou nas palavras-chaves as expressões gestão escolar, gestão da escola, administração escolar ou administração da escola. Esta primeira etapa nos disponibilizou duzentos e nove artigos. A opção por focalizar em artigos científicos publicados em revistas se embasa no entendimento que estes apresentam o resultado de uma ou mais pesquisas realizadas. Ademais, diferentemente dos artigos apresentados em eventos e publicados nos anais, os artigos publicados em revistas científicas tem a oportunidade de ajustar possíveis incoerências e 


\section{A UTILIZAÇÃO DO ESTUDO DE CASO EM PESQUISAS SOBRE GESTÃO ESCOLAR \\ DOI: http://dx.doi.org/10.5007/1983-4535.2015v8n2p177}

melhorar o conteúdo da pesquisa a partir da indicação dos pares que o avaliam, portanto, tendem a ser mais consistentes.

A segunda etapa consistiu em selecionar os artigos que se enquadram aos objetivos desta pesquisa. Para isto, o primeiro passo foi identificar os artigos que efetivamente se tratam de gestão escolar, pois muitos citam as expressões mencionadas acima, no entanto, abordam aspectos secundários da gestão escolar, como é o caso das pesquisas que se aprofundam na gestão de materiais escolares, na gestão da nutrição escolar, dentre outros campos que não fazem parte do interesse do presente estudo. Importante mencionar a definição constitutiva de Gestão Escolar se embasa no conceito de Ribeiro e Chaves (2012), qual seja: é o processo que operacionaliza e implementa as ações e políticas da unidade escolar. Na sequência, foram excluídos os artigos que não se tratavam da realidade brasileira, pois, mesmo publicados em revistas científicas do Brasil, muitos artigos apresentavam casos de escolas portuguesas. Deste modo, selecionamos quarenta e oito artigos que efetivamente abordam a gestão escolar na realidade brasileira.

Por fim, na terceira etapa, identificamos os artigos que utilizam o estudo de caso como método de pesquisa. Neste momento surgiram as primeiras dificuldades no processo de seleção, pois a maioria dos artigos não apresenta o processo metodológico no título e no resumo. Assim, para selecionar aqueles que efetivamente empregaram o estudo de caso, tornou-se necessário analisar integralmente os quarenta e oito artigos previamente selecionados. Diante deste processo, identificamos sete artigos que efetivamente empregam o estudo de caso para analisar a gestão de escolas brasileiras.

A análise destes artigos foi realizada em duas etapas. Em um primeiro momento, coletamos de modo meramente transcritivo os dados gerais de cada artigo, tais como: título do artigo; nome dos autores; campo de conhecimento e a instituição nas quais os autores atuam; a revista científica e o ano no qual o artigo foi publicado; o objetivo da pesquisa; e o caso investigado pelos pesquisadores. Posteriormente, analisamos qualitativamente a utilização do método a partir das seguintes categorias de análise:

a) a pesquisa é aprofundada (EISENHARDT, 1989; STAKE, 2000; GODOY, 2006; YIN, 2009)?

b) trata-se de estudo de caso único ou múltiplo (YIN, 2009)?

c) o artigo apresenta o contexto do caso (STAKE, 2000)?

d) o caso pode ser considerado paradigmático (FLYVBJERG, 2006) e representativo (EISENHARDT, 1989; STAKE, 2000)? 
e) qual o argumento para empregar o estudo de caso como estratégia de pesquisa (YIN, 2009)?

f) o estudo de caso se configura como intrínseco, instrumental ou coletivo (STAKE, 2000)?

g) em relação aos objetivos, a pesquisa se configura como descritiva, interpretativa ou avaliativa (GODOY, 2006)?

h) a pesquisa é qualitativa, quantitativa ou quali-quanti (BRYMAN, 1988)?

i) quais os métodos de coleta de dados? Utiliza múltiplos métodos (GODOY, 2006; YIN, 2009)?

j) quem são os sujeitos de pesquisa (GODOY, 2006)?

k) os autores descrevem como foram analisados os dados? Os dados foram categorizados (BARDIN, 1977)? Houve triangulação dos dados (STAKE, 2000; AMIS; SILK, 2008; YIN, 2009)? Foi utilizado algum software como apoio para esta análise (KELLE, 2004)?

1) utiliza práticas disciplinadas para empregar o estudo de caso como estratégia de pesquisa (EISENHARDT, 1989; STAKE, 2000; YIN, 2009)?

m) os autores buscam responder aos critérios que atestam a qualidade do estudo de caso, tais como fidedignidade, validade interna e validade externa (GODOY, 2006) ou credibilidade, transferência e dependência (LINCOLN; GUBA, 1985)?

Portanto, a partir deste processo metodológico, foi possível analisar como estudo de caso vem sendo utilizado nas pesquisas sobre gestão escolar na realidade brasileira.

\section{ANÁLISE DOS DADOS}

Este capítulo apresenta as duas etapas nas quais os artigos selecionados foram analisados. Assim, a primeira seção expõe os dados gerais de cada artigo e a segunda seção exprime a os detalhes da análise qualitativa do uso do estudo de caso.

\subsection{BREVE APRESENTAÇÃO DOS ARTIGOS ANALISADOS}

A primeira obra analisada refere-se ao artigo "Gestão do conhecimento no contexto da gestão escolar: estudo de caso de uma escola pública”, publicado em 2012 na Revista Perspectivas em Gestão \& Conhecimento, avaliada no Qualis CAPES como B2 na área de Educação. O artigo foi desenvolvido por Márcio José Dos Santos e Claudio Paixão Anastácio 
De Paula, que atuam no campo de conhecimento da Ciência da Informação e são vinculados à Universidade Federal de Pernambuco. Nesta obra, os autores objetivaram identificar as práticas de gestão escolar compatíveis com a gestão do conhecimento em uma escola pública da Região Noroeste do Estado de Minas Gerais que conquistou um prêmio em gestão escolar em 2004.

O segundo artigo refere-se à pesquisa de Luis Paulo Faria Carmo, Carlos Eduardo Pires De Faria e Fernando Pereira Tostes, que atuam na área de Ciências Contábeis da Universidade do Estado do Rio de Janeiro. Trata-se do artigo "Contribuição a Construção de Indicador de Desempenho no Setor Público: Estudo de Caso no Colégio Militar do Rio de Janeiro", publicado em 2008 na Revista Contabilidade, Gestão e Governança, avaliada como B2 em Administração, Ciências Contáveis e Turismo, e visa contribuir para a construção de um modelo conceitual de indicador de desempenho que atenda as necessidades gerenciais do setor público.

O terceiro artigo analisado tem como título "Desdobramentos da associação públicoprivado na administração do ensino técnico no Ceará", publicado em 2008 na Revista Cadernos de Pesquisa, avaliada como A1 em Educação. Esta pesquisa, realizada por Dagmar M. L. Zibas, que atua na área de Educação na Universidade de São Paulo e na Fundação Carlos Chagas, teve como objetivo apreender os processos institucionais de apropriação das orientações dos órgãos centrais e intermediários para a educação técnica de nível médio em uma escola situada no interior do Ceará.

A próxima obra diz respeito à pesquisa de Carolina Barbosa Montenegro, Kleber Cavalcanti Nóbrega e Tereza Souza, que atuam na área de Administração e estão vinculados à Universidade Potiguar. Trata-se do artigo “A gestão estratégica em educação e seus impactos na prestação dos serviços", publicado em 2010 na Revista Iberoamericana de Estratégia, classificado como B2 em Administração, Ciências Contáveis e Turismo. O objetivo é analisar como as estratégias desenvolvidas numa escola particular confessional católica são refletidas na qualidade dos serviços oferecidos, na visão dos gestores.

Já o quinto artigo tem como título "Programa Escola Campeã na Gestão Escolar: o Hibridismo entre a Racionalidade Burocrática e uma Anarquia Organizada", publicado em 2008 na Revista Gestão \& Tecnologia, Qualis B2 em Administração, Ciências Contábeis e Turismo. O artigo é de autoria de Andreia Pereira De Almeida, Gelson Silva Junquilho e Susane Petinelli Souza, que combinam a formação tanto em Educação quanto em Administração e atualmente atuam na Universidade Federal do Espírito Santo e na 
Universidade Federal de Minas Gerais. O artigo visa identificar os significados do programa de gestão escolar Escola Campeã na compreensão dos atores sociais envolvidos em uma escola pública municipal.

A sexta obra analisada refere-se ao artigo desenvolvido por Claudia Lopes Da Silva e Maria Isabel Da Silva Leme, da área de Psicologia e Educação da Universidade de São Paulo. $\mathrm{O}$ artigo, "O papel do diretor escolar na implantação de uma cultura educacional inclusiva", foi publicado em 2009 na Revista Psicologia: Ciência e Profissão, avaliada como B1 em Educação e em Administração, Ciências Contábeis e Turismo. Seu objetivo é compreender o papel do diretor escolar na formação de uma cultura escolar inclusiva em uma determinada diretoria escolar.

Por fim, o último artigo estudado diz respeito à obra de Ângela Maria Martins: “O contexto escolar e a dinâmica de órgãos colegiados: uma contribuição ao debate sobre gestão de escolas". A autora atua na área da Educação na Universidade Estadual de Campinas e, neste artigo, visou compreender o campo de tensão constituído no contexto escolar, considerando as relações instauradas entre direção, professores, coordenadores pedagógicos, pais e alunos quando reunidos em órgãos colegiados e reuniões pedagógicas coletivas em um Centro Estadual de Educação Tecnológica Paula Souza. O artigo foi publicado em 2008 na revista Ensaio (Fundação Cesgranrio. Impresso), classificada como A1 em Educação e B1 em Administração, Ciências Contábeis e Turismo.

\subsection{ANÁLISE QUALITATIVA DA UTILIZAÇÃO DO ESTUDO DE CASO}

Iniciamos a análise qualitativa identificando o nível de aprofundamento dos artigos selecionados, pois, segundo Eisenhardt (1989), Stake (2000), Godoy (2006) e Yin (2009), uma das principais vantagens do estudo de caso é compreender o fenômeno em profundidade. Nossa avaliação indica que, além de delimitar um caso específico, os sete artigos selecionados investigam o caso de modo aprofundado e, portanto, revelam os detalhes do processo de gestão escolar. Esta constatação vem ao encontro da nossa proposição inicial, ou seja, o estudo de caso, por ser um método que analisa intensivamente uma determinada unidade social, se trata de uma possibilidade consistente para compreender os fenômenos que permeiam a prática da gestão nas unidades escolares.

É importante destacar que todos os artigos se configuram como estudo de caso único. Não obstante, embora não haja indícios que demonstrem que os pesquisadores tiveram dificuldade em delimitar o caso, constatamos que dois artigos não apresentam o contexto no 
qual a gestão escolar se incorpora. De acordo com Stake (2000), o caso é uma entidade complexa que faz parte de um sistema cujas partes se envolvem, logo, entendemos que seria oportuno apresentar os limites do fenômeno analisado.

Além disto, os autores não esclarecem se o caso investigado é paradigmático, como aponta Flyvbjerg (2006), e representativo, como indicam Eisenhardt (1989) e Stake (2000). A partir da leitura dos artigos não é possível perceber a utilização das diretrizes que ajudam os pesquisadores a definir o caso. Embora não esteja explícito, constatamos alguns argumentos que ajudam a compreender a definição do caso em dois artigos. No primeiro, o objeto de pesquisa se trata de um caso considerado exemplar - a Escola em questão conquistou um prêmio de Gestão Escolar e, portanto, os autores afirmam que suas práticas de gestão devem ser seguidas por outras unidades escolares; enquanto no segundo artigo, foi possível constatar que um dos autores trabalha na organização objeto de estudo - Colégio Militar do Rio de Janeiro, ou seja, possivelmente o caso foi definido levando em consideração a conveniência dos autores.

Não obstante, três artigos não apresentam os motivos que levaram os autores a optar pelo emprego do estudo de caso. Em relação ao restante dos artigos, (1) os autores argumentam que o método seria a melhor opção para apresentar os detalhes da prática da gestão escolar de um caso exemplar; (2) que o estudo de caso proporciona a vantagem de reafirmar modelos, teorias e hipóteses, que na atualidade se desenvolvem sem suficientes dados e observações; (3) que para alcançar o objetivo da pesquisa é necessário analisar o caso em profundidade; e, por fim, (4) que o caráter exploratório dos objetivos indica que o estudo de caso seria o método mais adequado. Portanto, os autores de dois artigos usam argumentos parecidos com o que concebe Yin (2009), embora não o cite, isto é, a prática do estudo de caso seria adequada para responder questões do tipo "como" ou "por que", em pesquisas que o investigador possui pouco controle sobre os fenômenos e quando o foco de análise trata-se de um fenômeno contemporâneo em uma determinada realidade.

Ainda que os autores também não apresentem explicitamente o tipo de estudo de caso de acordo com o seu objetivo, constatamos que em mais de $70 \%$ dos casos analisados o estudo de caso se configura como intrínseco, enquanto o restante é instrumental. De acordo com Stake (2000), isto significa afirmar que cinco artigos visam compreender um determinado caso pelo interesse dos pesquisadores, ao tempo que dois artigos objetivam compreender um fenômeno mais amplo ou até mesmo avançar em uma teoria. Tal fato abre margem para as inúmeras críticas sobre o uso do método, pois o estudo de caso não está sendo 
utilizado para o desenvolvimento de novas teorias, mas sim testes de teorias já existentes, o que vem ao encontro dos achados de pesquisa de Consoli et al. (2008). Entretanto, o próprio Stake (2000) assinala que, independente do método, a maior parte das pesquisas é realizada por indivíduos que tem interesse intrínseco no caso e pouco interesse no avanço da ciência.

Em relação aos objetivos, cinco artigos se caracterizam pelo caráter interpretativo e dois pela sua essência descritiva. Esta categoria de análise se embasa na concepção de Godoy (2006), que concebe que os objetivos da pesquisa podem ser descritivos, interpretativos ou avaliativos. Deste modo, verificamos que os autores apenas descrevem ou interpretam como ocorre a prática da gestão escolar, enquanto nenhum dos artigos analisados efetivamente a avalia.

Outro achado de pesquisa que merece destaque é o fato de todos os artigos analisados se caracterizarem como qualitativos. Importante mencionar que os conceitos de qualitativo, quantitativo e qualitativo-quantitativo seguem os pressupostos de Bryman (1988). Ou seja, embora o estudo de caso seja uma estratégia de pesquisa qualitativa que permite a utilização de dados quantitativos no seu processo de pesquisa (YIN, 2009), nenhum dos artigos analisados se embasou em dados quantitativos e, portanto, se caracterizam exclusivamente como qualitativos.

Esta prerrogativa está intimamente relacionada com os métodos de coleta de dados. A esse respeito, torna-se relevante ressaltar o emprego da entrevista semi-estruturada, da pesquisa documental e da observação. Em seis - das sete pesquisas analisadas - consta a utilização da entrevista semi-estruturada como principal instrumento de coleta de dados, sendo que em cinco destes casos os pesquisadores utilizaram a pesquisa documental e em três a observação como métodos complementares. $\mathrm{O}$ único que não exprime o uso da entrevista semi-estruturada é justamente o caso do segundo artigo analisado, no qual o autor é ao mesmo tempo pesquisador e sujeito de pesquisa. Esta constatação vem ao encontro das concepções de Eisenhardt (1989), Godoy (1995) e Yin (2009), que concordam que a entrevista é uma das fontes mais importantes para uma pesquisa caracterizada pelo estudo de caso. Não obstante, constata-se que todas as pesquisas analisadas empregaram múltiplos instrumentos de coleta de dados, conforme indicam Godoy (1995) e Yin (2009).

No que diz respeito aos sujeitos de pesquisa, foi possível constatar que a maioria das pesquisas tem como foco central o nível estratégico das escolas, sendo que em dois artigos os autores não expõem os sujeitos de pesquisa. Um caso se trata, novamente, do segundo artigo analisado, enquanto o outro se refere à pesquisa que aborda o caso do Centro Estadual de 


\section{A UTILIZAÇÃO DO ESTUDO DE CASO EM PESQUISAS SOBRE GESTÃO ESCOLAR \\ DOI: http://dx.doi.org/10.5007/1983-4535.2015v8n2p177}

Educação Tecnológica Paula Souza. As demais pesquisas analisadas focalizaram a visão dos diretores da escola, sendo que em dois casos foram ouvidos também os coordenadores, os professores e os funcionários. Em apenas um destes casos os pesquisadores entrevistaram os alunos, os pedagogos, os secretários escolares e integrantes da Secretária de Educação. Portanto, embora muito se discuta sobre a gestão democrática nas escolas, o que se percebe são pesquisas científicas, especialmente nos estudo de casos analisados, que focalizam a perspectiva da cúpula estratégica das escolas, ou seja, os diretores escolares e, em segunda instância, os coordenadores escolares.

Não obstante, pudemos verificar que, com exceção do artigo em que o pesquisador era funcionário da unidade escolar pesquisada, todos os demais analisam os dados a partir de categorias de análise embasadas na literatura. Inclusive, os autores de dois artigos descrevem o processo de categorização realizado na análise dos dados a partir das concepções de Bardin (1977). Em um dos artigos analisados, os pesquisadores apenas apresentam o resultado em forma de categorias de análise, mas não relatam como os dados foram analisados. De todo modo, podemos concluir que a grande maioria das pesquisas analisadas utiliza categorias de análise previamente definidas para coletar e analisar os dados coletados, bem como para apresentar os resultados da pesquisa. Entretanto, nenhum artigo exprime o uso de software como apoio para esta análise, o que vai de encontro às prerrogativas de Kelle (2004).

Por fim, identificamos que não constam indícios da perspectiva positivista nos artigos analisados. Esta afirmação se embasa na ausência de três fatores: em primeiro lugar, os autores não indicam ter realizado qualquer triangulação dos dados coletados, ainda que tenham utilizado diferentes fontes de dados; em segundo lugar, não apresentam o uso de práticas disciplinadas para empregar o estudo de caso como estratégia de pesquisa, como, por exemplo, o referencial metodológico clássico de Eisenhardt (1989) ou de Yin (2009); e, em terceiro lugar, em nenhum dos artigos os autores buscam responder aos critérios que atestam a qualidade do estudo de caso, tais como fidedignidade, validade interna e validade externa, como aponta Godoy (2006), ou credibilidade, transferência e dependência, como sugerem Lincoln e Guba (1985).

Não podemos afirmar que as omissões destas diretrizes representam que todos os artigos analisados se configuram como críticos, conforme concebem Séguin e Chanlat (1992). Contudo, o fato de se distanciar dos padrões ontológicos e metodológicos, nos indica certo distanciamento também da perspectiva epistemológica positivista. Deste modo, considerando único e exclusivamente o conteúdo apresentados nos artigos e de acordo com a concepção 
biparadigmática de Séguin e Chanlat (1992), as sete pesquisas analisadas estariam mais próximas da perspectiva crítica do que da perspectiva funcionalista.

\section{CONSIDERAÇÕES FINAIS}

Este artigo visou avaliar como está sendo utilizado o estudo de caso nas pesquisas sobre gestão escolar na realidade brasileira. Assim como concebem Barbosa et al. (2014), Brasil (2014) e Todos Pela Educação (2014), entendemos que a gestão escolar é uma das principais vertentes que pode promover a qualificação da educação. Destarte, para compreender esta prática, é necessário analisar de modo intensivo e aprofundado este fenômeno, portanto, os métodos qualitativos se destacam.

Deste modo, após pesquisa nas principais bases de dados nacionais, identificamos sete artigos que se enquadram nas características previamente estabelecidas. Estas pesquisas foram avaliadas a partir de dois momentos. Inicialmente, coletamos os dados gerais dos artigos em caráter meramente descritivo. O segundo passo, então, foi analisar qualitativamente as diretrizes do estudo de caso aplicadas nestes artigos e identificar se os pesquisadores seguem às concepções discutidas na literatura.

No que se refere aos dados gerais destes artigos, percebemos que grande parte dos autores tem sua formação na área da Educação, como é o caso de Dagmar M.L. Zibas, de Claudia Lopes da Silva, de Andreia Pereira de Almeida, de Susane Petinelli Souza e de Angela Maria Martins. Embora em menor número, merece destaque também a quantidade de autores com formação em Administração, tais como: Carolina Barbosa Montenegro, Kleber Cavalcanti Nóbrega, Tereza Souza e Gelson Silva Junquilho. Neste sentido, chama a atenção o fato que dos quatro artigos desenvolvidos por pesquisadores da área de Educação, dois foram publicados em revistas qualificadas como A1 pela CAPES, o que nos remete a conclusão que a temática recebe atenção nos principais periódicos da área.

Em contrapartida, não foi possível identificar se a análise da gestão escolar a partir da utilização do estudo de caso é mais utilizada em determinadas localidades e instituições, haja vista que os autores dos artigos analisados estão vinculados nas mais diversas Universidades e regiões do Brasil. Não se percebe, também, indícios de maior aceitação por parte das revistas científicas por pesquisas que se enquadram no escopo deste trabalho, pois os sete artigos foram publicados em sete diferentes revistas. O que se constata, porém, é que os artigos analisados são relativamente recentes, todos foram publicados a partir de 2008, o que possivelmente está relacionado com as discussões do Plano Nacional de Educação, 


\section{A UTILIZAÇÃO DO ESTUDO DE CASO EM PESQUISAS SOBRE GESTÃO ESCOLAR \\ DOI: http://dx.doi.org/10.5007/1983-4535.2015v8n2p177}

sancionado pelo Poder Executivo este ano, mas que começou a ser discutido em meados de 2007.

No que diz respeito à análise qualitativa do estudo de caso nos artigos selecionados também foi possível identificar algumas diretrizes que merecem destaque. De início, é oportuno relatar que todas as pesquisas analisadas efetivamente se aprofundam na temática e trazem à tona detalhes importantes da Gestão Escolar. Além disto, todos os artigos se configuram como estudo de caso único, embora os casos investigados nestas pesquisas não se configurem como paradigmáticos ou representativos. Esta análise também nos indicou que apenas três artigos podem ser considerados instrumentais, ou seja, visam evoluir com uma determinada teoria. Outro achado que merece destaque é o fato de nenhuma das pesquisas analisadas se configurarem como avaliativa no que se refere aos objetivos, ou seja, apenas descrevem ou interpretam o fenômeno.

Também foi possível identificar que todas elas se configuram como qualitativa e empregam múltiplos instrumentos de coleta de dados, dos quais se destacam a entrevista-semi estruturada, a observação e a pesquisa documental. Embora muito se discuta sobre gestão democrática no contexto da gestão escolar, os sujeitos de pesquisa da maioria dos artigos analisados referem-se à cúpula estratégica da organização. Não obstante, a maioria dos autores descreve como os dados foram analisados, sendo que o processo de análise a partir das categorias de análise se destaca. Por fim, constatamos que os autores não apresentam indícios característicos da perspectiva epistemológica positivista.

Importante destacar que a maioria dos autores, sobretudo aqueles com formação na área da Educação, não apresentam o processo metodológico, tanto no que diz respeito às pesquisas empíricas quanto teóricas. Tal fato possivelmente prejudicou o processo de pesquisa deste artigo, pois provavelmente alguma pesquisa que tenha utilizado o estudo de caso para analisar a Gestão Escolar não foi selecionada para análise. Deste modo, ainda que tenhamos tomado todos os cuidados possíveis, a coleta destes artigos se embasou exclusivamente no conteúdo dos artigos, portanto, aqueles que não esclarecem os métodos utilizados infelizmente não foram selecionados e posteriormente analisados.

Assim, nossa pesquisa se restringiu a sete artigos que esclarecem e efetivamente empregam o estudo de caso para analisar a Gestão Escolar no contexto brasileiro, principalmente por compreendermos que os métodos qualitativos são os meios de pesquisas mais adequados para analisar esta temática. Deste modo, sugerimos que dentro deste escopo sejam realizados outros tipos de análises, como, por exemplo, investigar se as pesquisas sobre 
Gestão Escolar estão utilizando métodos como a etnografia, a pesquisa-ação e a grounded theory, e, caso estejam, analisar como estes métodos efetivamente estão sendo utilizados.

\section{REFERÊNCIAS}

ALVES, N; GARCIA, R. L (Org.). O sentido da escola. Rio de Janeiro: DP\&A, 2002.

ALVES-MAZZOTI, A. J. Usos e abusos do estudo de caso. Cadernos de pesquisa, v.36, n. 129, p. 637-651, 2006.

AMIS, J. M.; SILK, M. L. The Philosophy and Politics of Quality in Qualitative Organizational Research. Organizational Research Methods, v.11, n.3, p.456-480, 2008.

BARBOSA, L. S; CARNEIRO, R. F; PONTES, T. A.; VARGAS, D.; GROSTEIN, F.; CALEGARI, D.; LYRA, E.; VAZ, H.; COSTA, P.; SILVA, R. Mapa do buraco e a busca de soluções para sair dele, 2014. Disponível em:

$<$ http://pt.slideshare.net/mapadoburaco/mapa-doburaco-

38067009?utm_source=slideshow03\&utm_medium=ssemail\&utm_campaign=iupload_share_ slideshow>. Acesso em 21 ago. 2014.

BARDIN, L. Análise de conteúdo. Lisboa: Edições 70, 1977.

BRASIL. Ministério da Educação. Plano Nacional de Educação - PNE. Disponível em: < http://pne.mec.gov.br/pdf/pne_conhecendo_20_metas.pdf $>$. Acesso em 21 ago. 2014.

BRYMAN, A. Quantity and quality in social research. London: Unwin Hyman, 1988.

CENPEC - Centro de Estudos e Pesquisas em Educação, Cultura e Ação Comunitária.

Educação para todos: avaliação da década. Brasília: MEC/INEP, 2000. Disponível em: $<$ http://www.publicacoes.inep.gov.br/arquivos/\%7BDEBC5505-6B0E-4AF1-BCAE0D384B6AB419\%7D avaliacao 127.pdf>. Acesso em 10 ago. 2014.

CHENG, Y. C. A Topology of Three-Wave Models of Strategic Leadership in Education. International Studies in Educational Administration, v. 38, Issue 1, p. 35-54, 2010.

COELHO, M. I. M. Vinte anos de avaliação da educação básica no Brasil. Ensaio: aval. pol. públ. Educ., v. 16, n. 59, p. 229-258, 2008.

CONSOLI, M.A.; MUSTTI, M. A.; SCARE, R. F.; FRATANTONIO, W. A. Uma discussão sobre a utilização do estudo de caso como método de pesquisa em ciências gerenciais. XXXII EnANPAD, Rio de Janeiro, RJ., 2008. Disponível em:

$<$ http://www.markestrat.org/up_arqs/pub_20101118092005_umadiscusaosobreautilizacaodoe studodecaso.pdf $>$. Acesso em 18 ago $20 \overline{14}$.

EISENHARDT K. M. Building Theories form Case Study Research. Academy of Management Review, Vol. 14, No. 4, p. 532-550, 1989. 
FELDHAUS, D. C.; PEREIRA, M. F. Planejamento e estratégia das escolas: o que leva as escolas a terem alto desempenho. São Paulo: Atlas, 2013.

FLYVBJERG, Bent. Five Misunderstanding about case study research. In: SEALE, Clive et al. (Eds.) Qualitative research practice. London: Sage, 2004. p.420-434

Gerring, J.; McDermott, R. An experimental template for case study research. American Journal of Political Science, v.51, n. 3, p. $688-701,2010$.

GODOY, A. S. Estudo de caso qualitativo. In: GODOI, C. K.; BANDEIRA DE MELO, R.; SILVA, A. B. Pesquisa qualitativa em estudos organizacionais: paradigmas, estratégias e métodos. São Paulo: Saraiva, 2006.

INEP - Instituto Nacional de Estudos e Pesquisas Educacionais Anísio Teixeira. O que é o IDEB. Disponível em: < http://portal.inep.gov.br/web/portal-ideb/o-que-e-o-ideb $>$. Acesso em 16 ago. 2014.

KELLE, U. Análise com auxílio de computador: codificação e indexação. In: BAUER, M. W., GASKELL, G. Pesquisa qualitativa com texto, imagem e som: um manual prático. Petrópolis: Vozes, p. 393-415, 2004.

LIMA, P. D. B. Organizações públicas de qualidade. In: LEVY, E.; DRAGO, P. A. Gestão pública no Brasil contemporâneo. São Paulo: Fundap, 2005.

LINCOLN, Y. S.; GUBA E. G. Naturalistic inquiry. Beverly Hills: Sage, 1985.

LLEWELLYN, S.; NORTHCOTT, D. The singular view in management case studies qualitative research in organizations and management. An International Journal, v. 2, n. 3, p. 194-207, 2007.

LUCK, H. Perspectivas da Gestão Escolar e Implicações quanto à formação de seus gestores. Em aberto, Brasília, v. 17, n. 72, p. 11-33, fev/jun, 2000.

Gestão educacional: uma questão paradigmática. 3. ed. Petrópolis: Vozes, 2007.

MARIZ, L. A.; GOULART, S.; DOURADO, D.; REGIS, H. P. O reinado dos Estudos de Caso em Teoria das Organizações: Imprecisões e Alternativas. Cad. EBAPE.BR, v.3, n.2, Rio de Janeiro, 2005.

MARTINS, A. M. ; SILVA, V. G. Estado da Arte: gestão, autonomia da escola e órgãos colegiados (2000/2008). Cadernos de Pesquisa (Fundação Carlos Chagas. Impresso), v. 41, p. 228-245, 2011.

OCDE - Organização para Cooperação e DesenvolvimentoEconômico. About PISA. Disponível em: < http://www.oecd.org/pisa/aboutpisa/>. Acesso em 21 ago. 2014.

RIBEIRO, M. E. S.; CHAVES, V. L. J. Gestão educacional: modelos e práticas. In: III Congresso Ibero Americano de Política e Administração da Educação. Anais, Zaragoza Espanha, 2012. 
SÉGUIN, F.; CHANLAT, J. F. L'analyse des organisations: une anthologie sociologique. Les théories de l'organisation. Montréal: Gaetan Morin Editeur Limitee, 1992.

STAKE, R. E. Case studies. In: DENZIN, N. K. (Edit.); LINCOLN, Y. S.(Edit.). Handbook of qualitative research. Thousand Oaks: SAGE, 2000.

TODOS PELA EDUCAÇÃO. Indicadores da educação: 5 metas. Disponível em:

$<$ http://www.todospelaeducacao.org.br/indicadores-da-educacao/5-metas $>$. Acesso em 22 ago 2014.

TRIVIÑOS, A. N. Introdução à pesquisa em Ciências Sociais. São Paulo: Editora Atlas, 1987.

WATTS, Michael. They have tied me to a Stake: reflections on the art of case study research. Qualitative Inquiry, v.13, n.2, p.204-217, 2007.

YIN, R. K. Case study research, design and methods. Thousand Oaks. California: Sage Publications, 2009. 